\title{
(2) OPEN ACCESS \\ Data handling practices and commercial features of apps related to children: a scoping review of content analyses
}

\author{
Lindsay Jibb (1) , ${ }^{1,2}$ Elsie Amoako, ${ }^{1}$ Melissa Heisey, ${ }^{1}$ Lily Ren, ${ }^{3}$ Quinn Grundy ${ }^{1}$
}

\begin{abstract}
- Additional supplemental material is published online only. To view, please visit the journal online (http://dx.doi. org/10.1136/archdischild2021-323292)

Lawrence S. Bloomberg Faculty of Nursing, University of Toronto, Toronto, Ontario, Canada

${ }^{2}$ Child Health Evaluative Sciences, Hospital for Sick Children, Toronto, Ontario, Canada

${ }^{3}$ Lane Medical Library and Knowledge Management Center, Stanford University, Stanford, California, USA
\end{abstract}

\section{Correspondence to}

Dr Lindsay Jibb, Lawrence $S$. Bloomberg Faculty of Nursing, University of Toronto, Toronto, Canada;

lindsay.jibb@sickkids.ca

Received 27 September 2021 Accepted 21 January 2022
D) Check for updates

(C) Author(s) (or their employer(s)) 2022. Re-use permitted under CC BY-NC. No commercial re-use. See rights and permissions. Published by BMJ.

\section{To cite: Jibb L, Amoako $E$,}

Heisey $M$, et al.

Arch Dis Child Epub ahead of print: [please include Day

Month Year]. doi:10.1136/

archdischild-2021-323292

\section{ABSTRACT}

Background Child interaction (including via parent proxy) with mobile apps is common, generating concern about children's privacy and vulnerability to advertising and other commercial interests. Researchers have conducted numerous app content evaluations, but there is less attention to data sharing or commercial practices. Objective This scoping review of commercial app evaluation studies describes the nature of such evaluations, including assessments of data privacy, data security and app-based advertising.

Methods We searched Scopus, PubMed, Embase and ACM Digital Library (2005-2020). We included studies that evaluated the properties of apps available through commercial app stores and targeted children, parents of a child (0-18 years) or expectant parents. Data extracted and synthesised were study and app user characteristics, and app privacy, data sharing, security, advertisement and in-app purchase elements.

Results We included 34 studies; less than half ( $n=15$; $44.1 \%$ ) evaluated data privacy and security elements and half ( $n=17 ; 50.0 \%$ ) assessed app commercial features. Common issues included frequent data sharing or lax security measures, including permission requests and third-party data transmissions. In-app purchase options and advertisements were common and involved manipulative delivery methods and content that is potentially harmful to child health.

Conclusions Research related to the data handling and the commercial features of apps that may transmit children's data is preliminary and has not kept pace with the rapid expansion and evolution of mobile app development. Critical examinations of these app aspects are needed to elucidate risks and inform regulations aimed at protecting children's privacy and well-being.

\section{INTRODUCTION}

Today's children are growing up in an immersive digital media era where frequent interaction with mobile applications (apps) is the norm. In addition to their own use of technology, children's data including photographs, videos and personal information are shared via their parents' online behaviours. Engagement with technology spans childhood, with $49 \%$ of parents using parenting apps, ${ }^{1} 60 \%$ of children less than 3 years having used a mobile device ${ }^{2}$ and, in the UK, $53 \%$ of children aged 7 years and $90 \%$ of children aged 11 years reporting mobile phone ownership. ${ }^{3}$ Unfortunately, children and their parents are generally engaging with apps without a fulsome understanding of

\section{What is already known on this topic?}

Mobile app developers encourage users to enter personal information and routinely share collected data with third parties to enhance the user experience or monetise the app.

- Apps focused on children may be among the worst in terms of the number of associated third-party data trackers-posing privacy and safety concerns to children.

- Child and parent app content analyses are increasingly conducted, but little is known associated data privacy, data security and appbased advertising assessments.

\section{What this study adds?}

- Comprehensive evaluations of the data privacy and security elements and commercial features of apps that may transmit children's data are rarely conducted.

- When evaluated, child and parent apps show frequent data sharing and lax security measures, including permission requests and third-party data transmissions.

- In-app purchase options and advertisements appear common in child and parent apps and involved manipulative delivery methods and content that is potentially harmful to child's health.

the privacy implications of their actions or the commercial interests in monetising their app-based activities. $^{4}$

Mobile app developers encourage users to enter personal information and routinely share collected data with third parties to enhance the user experience or commercialise the app..$^{5}$ Adult apps are known to share personal and health information with an array of commercial entities, which are then capable of aggregating data across apps and re-identifying users. $^{6} 7$ Recognising children's particular vulnerabilities, regulations designed to protect child privacy include Europe's General Data Protection Regulation (GDPR) and the United States' Children's Online Privacy Protection Act (COPPA). These regulations require operators of online services such as apps to give detailed notice of privacy practices and prohibit the processing of children's personal information without consent. ${ }^{89}$ 
Still, evidence suggests that apps containing children's data are among the worst in terms of the number of associated thirdparty trackers ${ }^{10}$-and developers may skirt privacy regulation by claiming their app is targeted at general audiences rather than children. ${ }^{11}$

This mobile ecosystem and current regulatory situation creates serious risks to children. The ubiquitous online presence and purchasing power of young parents and children mean these groups are now at the centre of the e-commerce market. This is highly problematic as serious child privacy and safety issues may arise if information shared with apps is used for data-driven advertising. Furthermore, there is a real danger that data aggregators may create digital dossiers that follow young people into adulthood and impact their future education, employment and health insurance acquisition opportunities. ${ }^{12}$

In parallel with these data handling issues, research attention has increasingly turned to app stores and the content and quality of commercially available apps. Given the availability of such evaluations and that these apps may transmit child data to a host of third parties, the objective of this review was to understand the scope of such evaluations, including whether and how researchers are assessing data privacy, data security and appbased advertising and what results they are finding in these areas.

\section{METHODS}

\section{Design and reporting}

We conducted a scoping review according to the framework developed by Levac et al ${ }^{13}$ using an internal protocol that was based on a previous, similar review by a member of our group. ${ }^{14}$ Review reporting is in accordance with the PRISMA (Preferred Reporting Items for Systematic Reviews and Meta-Analyses) extension for scoping reviews (PRISMA-ScR) checklist. ${ }^{15}$

\section{Eligibility criteria}

We included studies that evaluated apps available in commercial stores which collected data directly related to children; thus users would be children, a parent of a child ( $0-18$ years) or an expectant parent. We excluded commentaries, topical or systematic literature reviews, protocols, book chapters and conference abstracts. No language restrictions were placed. The search was limited to studies published from 2005 onward-the timeframe where mobile apps have been publicly available. ${ }^{16}$

\section{Information sources and evidence screening}

On 18 November 2020, we conducted searches in the Scopus (Elsevier), PubMed, Embase (Ovid) and ACM Digital Library databases. Our search strategy was developed in consultation with a research librarian (online supplemental appendix 1) and piloted to validate applicability. We supplemented the search with searches of our own databases of mobile app literature. Using Covidence software, duplicates were removed and three authors independently screened titles and abstracts, and then full texts, in duplicate according to the eligibility criteria. Eligibility disagreements were resolved through discussion with a third reviewer.

\section{Data charting}

We developed, piloted and refined a data charting table with reference to those used in our previous research in this topic area $^{1417}$ and we charted data into this table. The data items charted are shown in online supplemental appendix 2 .

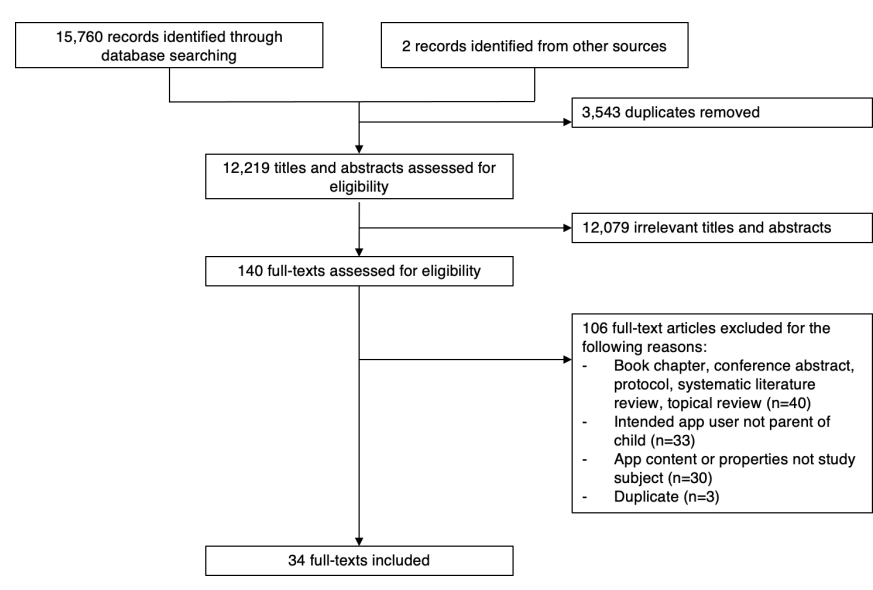

Figure 1 Study selection process.

\section{Synthesis of results}

Data abstraction fields were grouped according to key data features to enable synthesis. Quantitative data were summarised using descriptive statistics. Where appropriate, qualitative data items were categorised descriptively, and frequencies calculated. Charting and categorisation were conducted by one author and checked by a second author.

\section{RESULTS}

\section{Study selection}

We identified 15762 records across all databases (figure 1). After the removal of duplicate and screening of titles and abstracts, we assessed 140 full-text articles for inclusion. Following full-text screening, 34 articles were included in this review.

\section{Study and general app characteristics}

The number of published studies meeting our inclusion criteria has increased over time (figure 2). Study details are shown in table 1 . Studies were conducted in the USA $(\mathrm{n}=18 ; 52.9 \%)$, Australia ( $\mathrm{n}=9 ; 26.5 \%)$, Canada $(\mathrm{n}=2 ; 5.9 \%)$, Iran $(\mathrm{n}=1 ; 2.9 \%)$, India $(\mathrm{n}=1 ; 2.9 \%)$ and the UK $(\mathrm{n}=1 ; 2.9 \%)$. Two studies $(5.9 \%)$ were conducted across multiple countries. Most commonly, study designs were reported as systematic reviews or evaluations $(n=13 ; 38.2 \%)$, descriptive or content analyses $(n=10 ; 9.4 \%)$, or reviews $(n=5 ; 14.7 \%)$. Stated designs represented the authors' own labelling, and we did not find meaningful correspondences between reported study designs and the methods used. Study funding was from government agencies $(n=10 ; 29.4 \%)$, universities $(n=3 ; 8.8 \%)$, non-for-profit organisations $(n=1 ; 2.9 \%)$, for-profit organisations $(n=1 ; 2.9 \%)$ or a combination of these sources $(n=5 ; 14.7 \%)$. Nine studies $(26.5 \%)$ did not identify the funding source and $5(14.7 \%)$ received no funding.

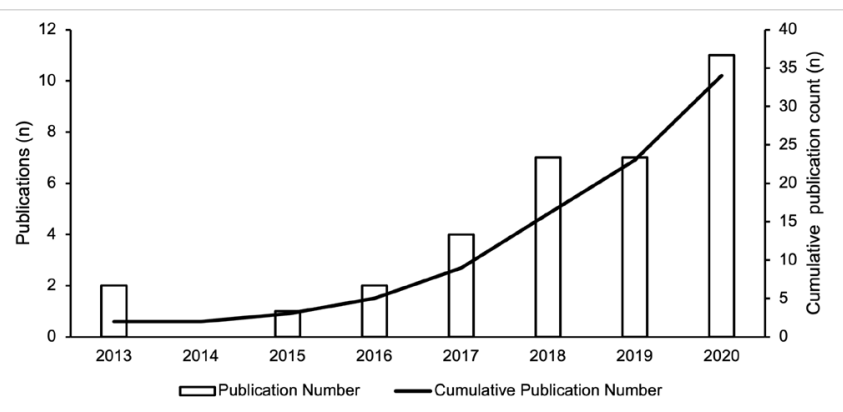

Figure 2 Study publication number over time. 


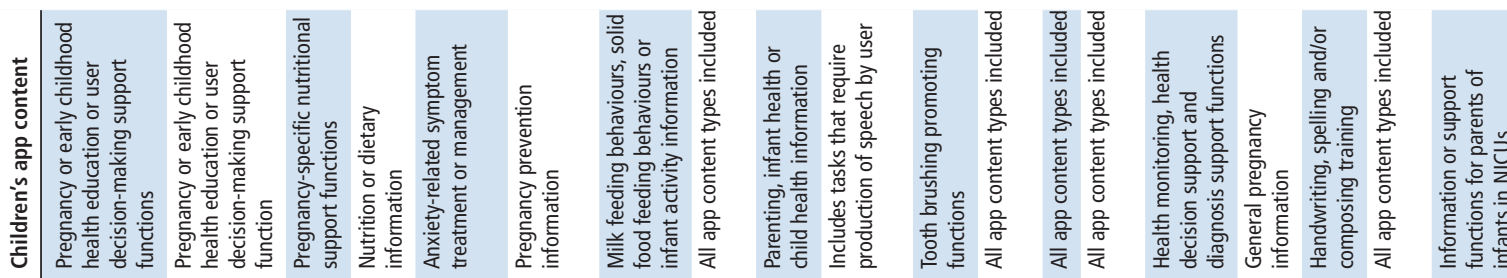

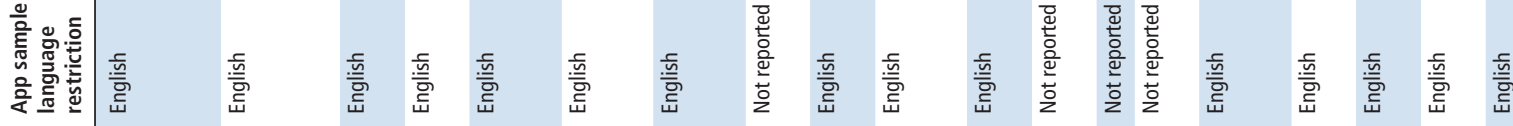

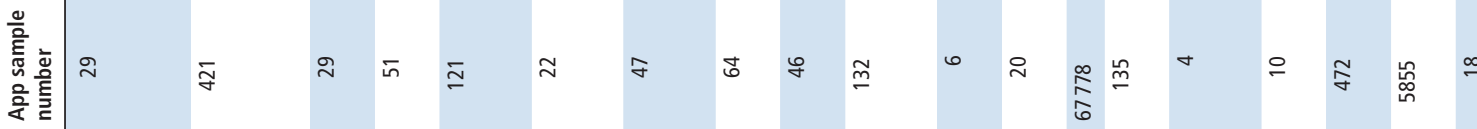

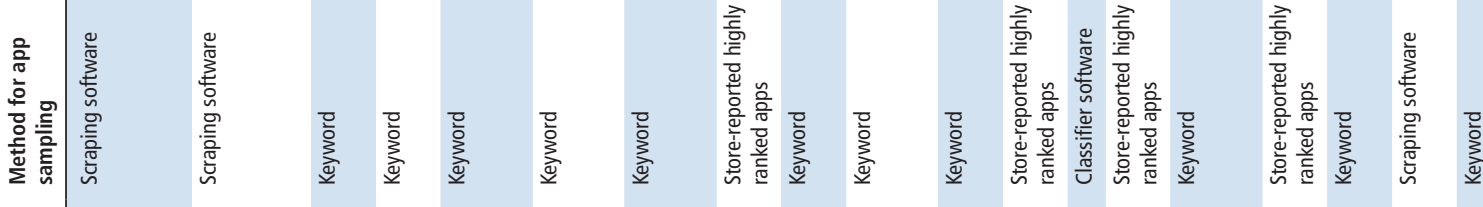

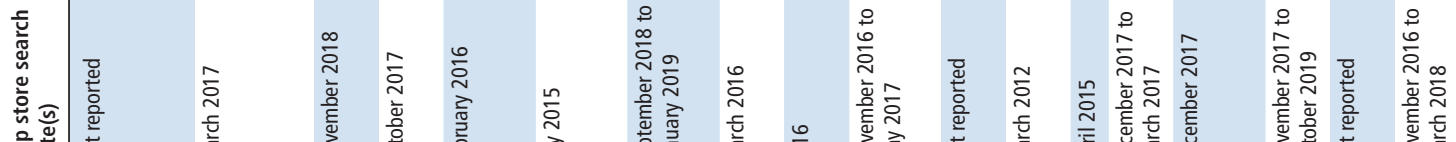

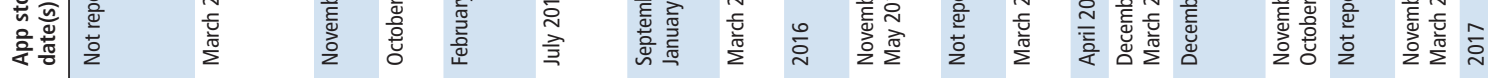

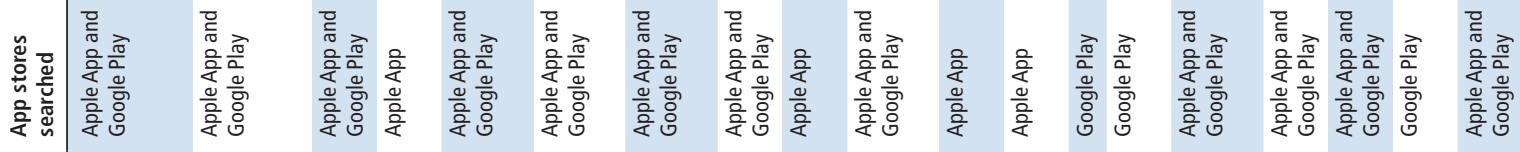

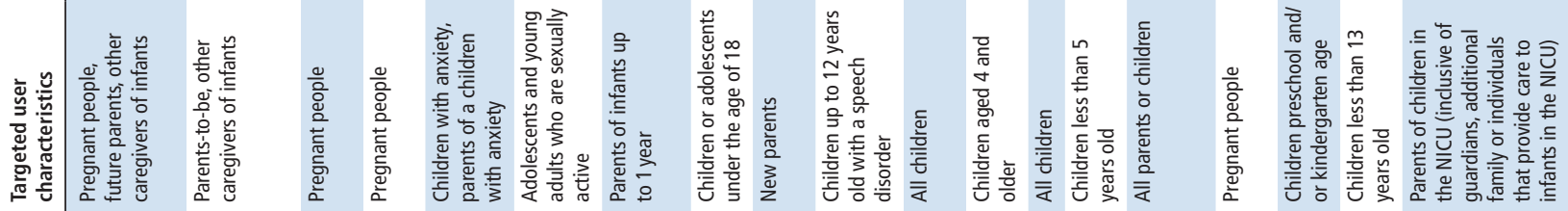

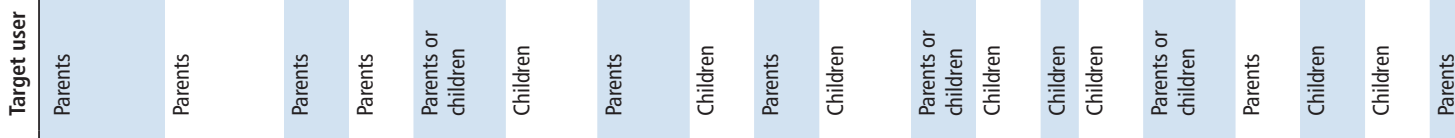

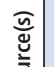

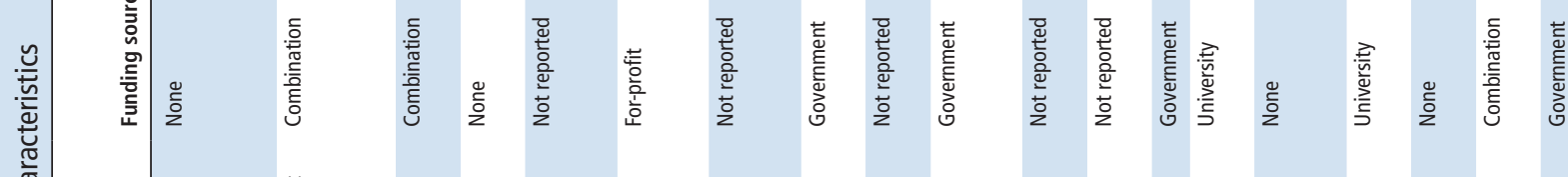

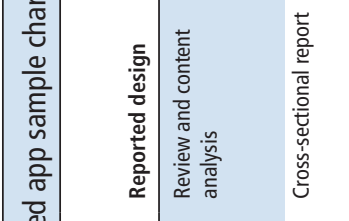

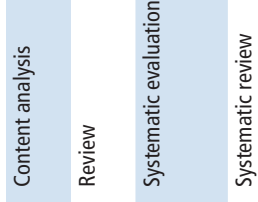

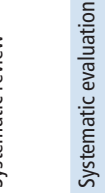

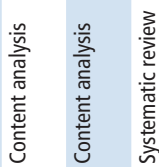

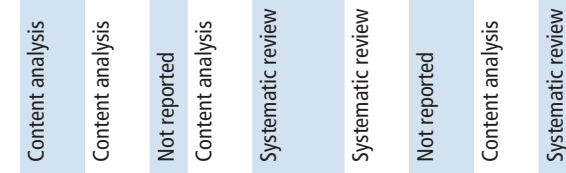

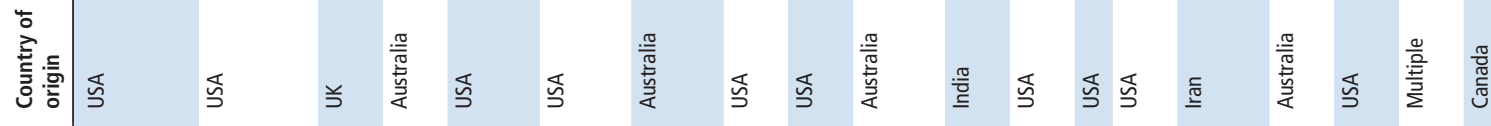

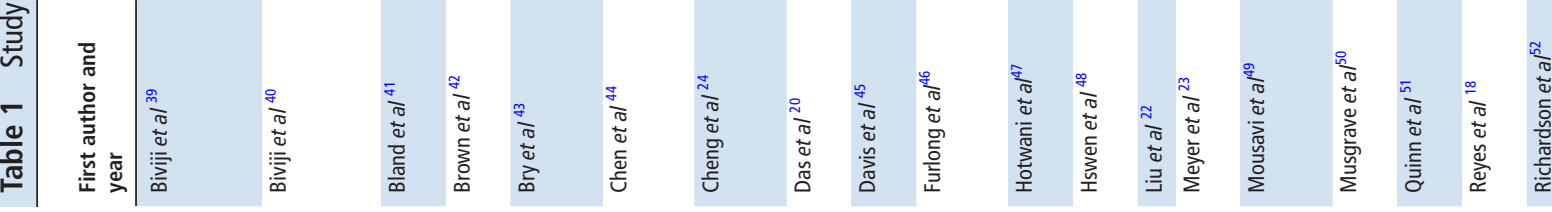




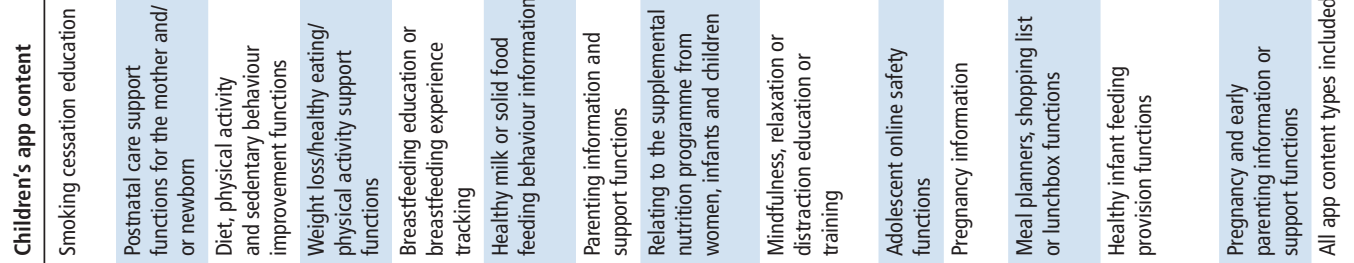

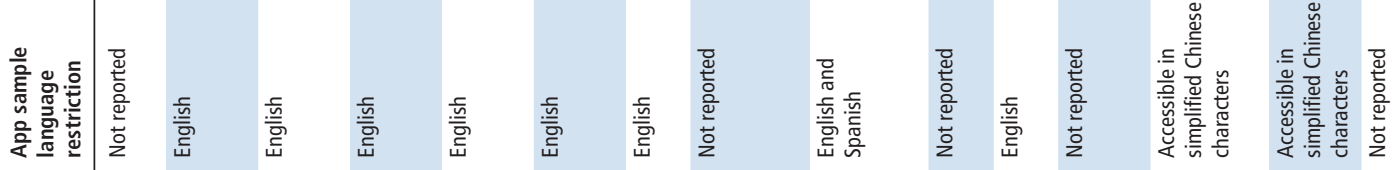

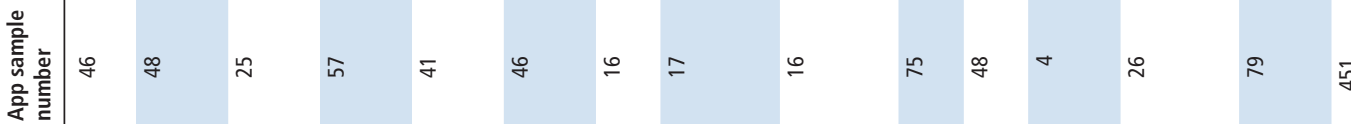

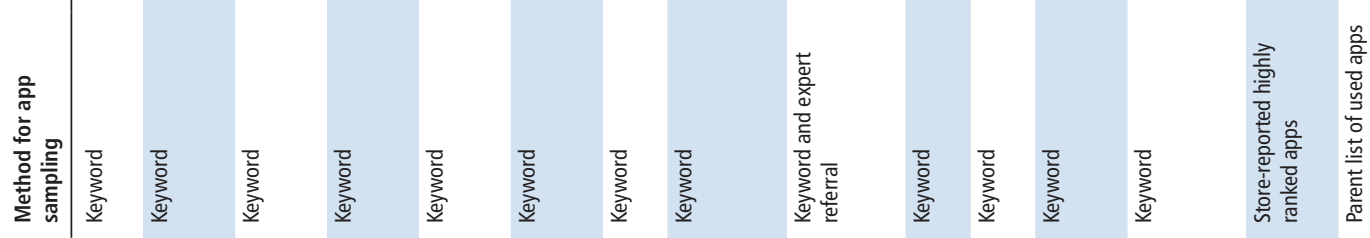

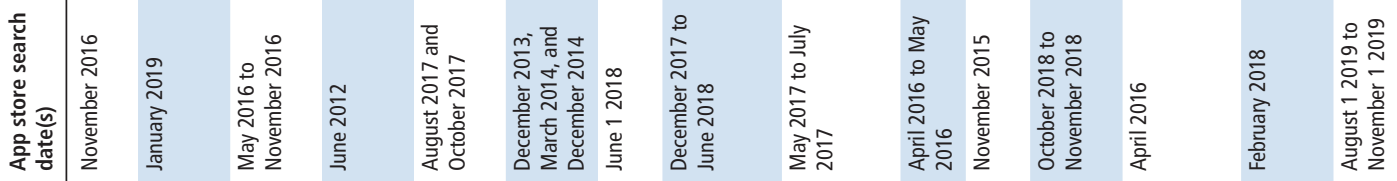

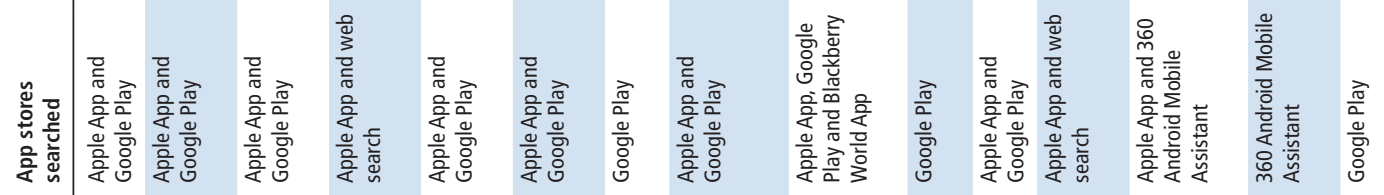

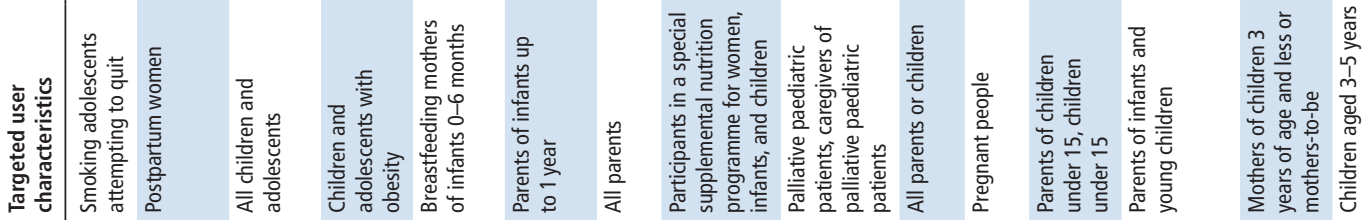

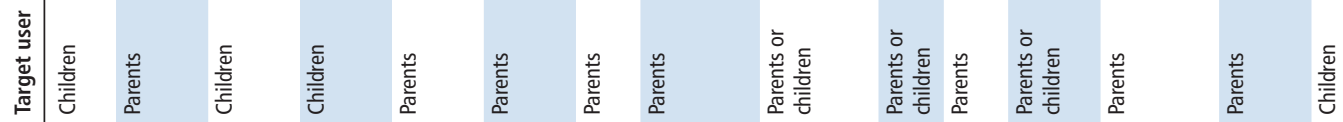

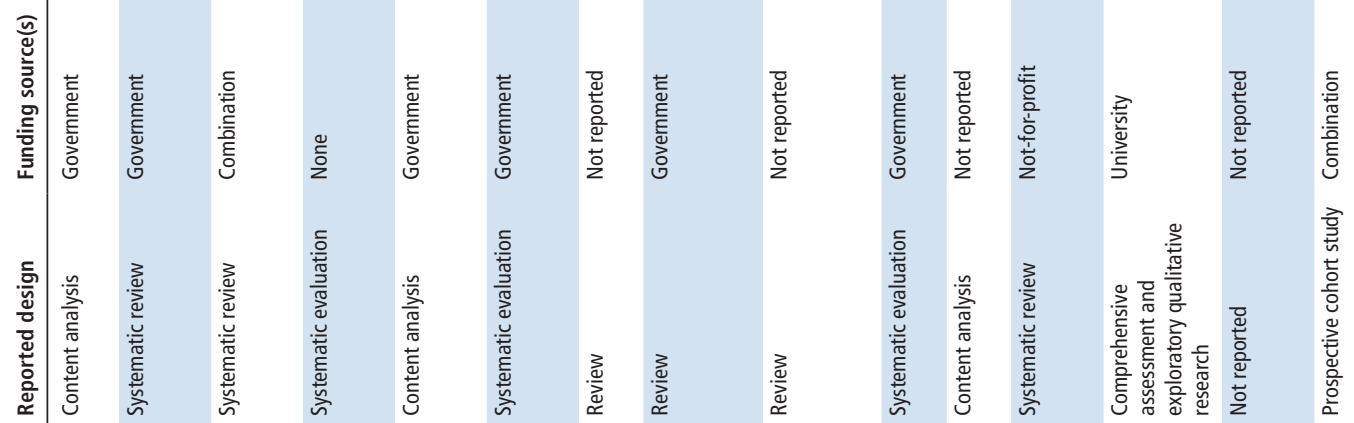

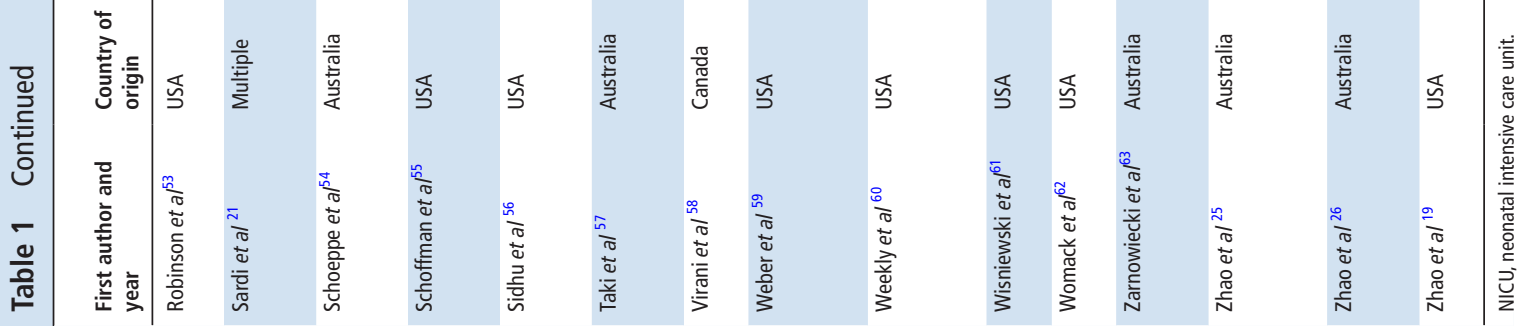


The median app sample size across studies was 46 (range 4-67778). Parents were the intended app users in 16 studies $(47.1 \%)$, children in 12 studies $(35.3 \%)$, and parents or children in 6 studies (17.6\%). Apps were most commonly available through both iTunes (Apple) and Google Play stores $(n=19$; $55.9 \%)$-followed by Google Play $(n=6 ; 17.6 \%)$ or iTunes alone $(\mathrm{n}=4 ; 11.8 \%)$. To sample apps, authors most commonly used keyword searches in app stores $(n=23 ; 67.6 \%)$, store-reported ranking lists $(\mathrm{n}=5 ; 14.7 \%)$ or software to support searching of app store contents $(\mathrm{n}=4 ; 11.8 \%)$.

\section{App data privacy and security-related findings}

Less than half $(n=15 ; 44.1 \%)$ of the studies evaluated any data privacy or security features. A total of two studies (5.9\%) evaluated apps' third-party data sharing practices. ${ }^{18} 19$ In both cases, studies automated the process of app execution using simulated data inputs and determined the number and domain destination of data transmissions. Results showed that $67 \%{ }^{19}$ and $73 \%{ }^{18}$ of apps transmitted children's personal data to third parties including those providing advertising-related services. Transmitted data included email addresses, information enabling user geolocation and advertising IDs that can be used to create behaviour profiles for advertising. Third-party transmission counts were not associated with child sex, parent age or marital status, or family income-to-needs ratio. However, transmissions were twofold to threefold higher in the case of children whose parents did not have advanced degrees. ${ }^{19}$

Table 2 shows other app privacy-related and security-related evaluation data from studies. Eight studies (23.5\%) reported on apps' capacity to share information via social media. These studies did not explicitly evaluate whether the nature of such sharing was active (ie, user-initiated data sharing for purposes including seeking peer support) or passive (ie, data transmission to social media networks unbeknownst to the app user). The potential to share data to social media platforms occurred in 14\%-63\% of apps (median 28\%).

Additionally, three studies (8.8\%) documented the presence of privacy policies and single studies (2.9\%) evaluated each of privacy policy content and readability. These studies showed 5\%-100\% of apps (median 63\%) had an associated privacy policy. Policy readability was poor ${ }^{20}$ and often failed to comply with international or federal regulations. ${ }^{21}$ Two studies $(5.9 \%)$ documented actual or potential permission requests, ${ }^{22} 23$ showing that permission requests occurred in up to $100 \%$ of apps and may violate jurisdictional privacy regulations such as location data tracking.

App data security features were evaluated in 29.4\% $(n=10)$ of studies and included presence of login or password protection element $(\mathrm{n}=7 ; 20.6 \%)$, login/password and cloud storage option $(n=1 ; 2.9 \%)$, or data encryption $(n=1 ; 2.9 \%)$, and the application of an investigator-developed security assessment scale $(\mathrm{n}=1 ; 2.9 \%)$. Security-related results showed: login or password protection presence in $0 \%-100 \%$ of apps (median: 31\%), high proportions of apps not protecting data transmissions using standard methods, ${ }^{18}$ and few apps with high security assessment scale ratings. ${ }^{24}$

\section{App commercial feature-related findings}

Commercial features were assessed in 17 studies (50.0\%) (table 3) and included the proportion of apps with in-app purchase options $(n=15 ; 44.1 \%)$, the proportion of apps with in-app advertisements $(n=10 ; 29.4 \%)$ and the type of advertisements $(n=3 ; 8.8 \%)$. In-app purchases and advertisements were present in 0\%-46\% (median 25\%) and 9\%-95\% (median $51 \%$ ) of apps, respectively. To evaluate advertisement content, all studies used manual content analysis using a predefined and investigator-developed advertising coding scheme. ${ }^{23} 2526$ Content analysis conducted by Meyer et a ${ }^{23}$ showed advertisements were presented using traditional methods (eg, product videos as shown on television) but also in insidious ways that might prompt further advertising consumption (eg, embedding advertising videos within gamified app features). In the two studies that assessed the relationships of advertisements to health outcomes, advertisements promoted formula-feeding for premature babies, toddlers or older children, ${ }^{25}{ }^{26}$ which may be in contravention of the WHO Code on the Marketing of Breast Milk Substitutes ${ }^{27}$ due to potentially harmful impacts on health.

\section{DISCUSSION}

Evaluations of the content and quality of commercially available apps that may transmit child data have proliferated steadily over time. Rigorous, independent evaluations of the data sharing practices and commercial features of these apps remain rare. However, there is rapid methodological development in the field and strategies to evaluate these practices are being increasingly developed and used by interdisciplinary research groups. ${ }^{10} 1819$

\section{Study and app characteristics}

Reviews of apps that collect, and potentially share, children's data are conducted most often by investigators in high-income, predominantly English-speaking countries, and commonly include only apps available in English. Most studies focused on understanding the content of apps designed for specific health or education purposes and few examined game-based and other types of apps children commonly engage with. Surrogate measures are largely used to evaluate the privacy and security features of apps as only a handful of studies have examined app data sharing and security practices directly. Still, our data show that, when data privacy and security evaluations are conducted, issues with frequent data sharing or lax security measures are uncovered.

\section{Data sharing practices}

Most researchers included only proxy measures for actual data sharing practices, such as permission requests or the presence of a privacy policy. In the few studies that measured actual data sharing, identifying children's data were provided to third parties. ${ }^{19}$ This is problematic as aggregation of these data can support the characterisation of parent and child users according to their app interaction patterns or demographics, and these characterisations may be commercially exploited to encourage impulse purchasing or suggest unhealthy products in ways that exacerbate health inequities. ${ }^{19} 28$

\section{Data sharing policies}

Privacy policies in child and parenting apps are variable in terms of both presence and readability. Thus, the data tracking and commercialisation practices of apps, and their associated risks, are generally unknown to children and adults alike $\mathrm{e}^{29-31}$ — challenging the value of the dominant 'notice and consent' privacy framework of the information age. Digital literacy skills-building may mitigate some risks to users and, in the case of children, such programmes have been developed. ${ }^{29}$ However, lower socioeconomic status, as well as age and gender, may be associated with lower digital literacy, ${ }^{31}$ suggesting that equitable access to literacy training remains elusive. In addition, even when privacy policies are present, they oftentimes do not reflect actual app data sharing behaviours. ${ }^{32} 33$ 
Table 2 App privacy-related and security-related evaluation methods and results

\begin{tabular}{|c|c|c|c|c|c|c|c|c|}
\hline & \multicolumn{2}{|l|}{ Privacy policy } & \multicolumn{2}{|c|}{ Social media } & \multicolumn{2}{|c|}{ Permissions requested } & \multicolumn{2}{|l|}{ Data security } \\
\hline & Methods & Results & Methods & Results & Methods & Results & Methods & Results \\
\hline Bry et $a l^{43}$ & $\begin{array}{l}\text { Evaluated app } \\
\text { store page and/ } \\
\text { or downloaded } \\
\text { app manually }\end{array}$ & $\begin{array}{l}\text { Privacy policy } \\
\text { presence: Less } \\
\text { than } 5 \% \text { of apps }\end{array}$ & & & & & $\begin{array}{l}\text { Evaluated app } \\
\text { store page and/or } \\
\text { downloaded app } \\
\text { manually }\end{array}$ & $\begin{array}{l}\text { Login and/or password } \\
\text { presence: Less than } 5 \% \\
\text { of apps }\end{array}$ \\
\hline Cheng et $a l^{24}$ & & & & & & & $\begin{array}{l}\text { Evaluated app } \\
\text { store page and/or } \\
\text { downloaded app } \\
\text { manually }\end{array}$ & $\begin{array}{l}\text { Investigator-developed } \\
\text { security assessment scale: } \\
6 \% \text { of apps rated as } \\
\text { excellent; } 10 \% \text { of apps rated } \\
\text { as good }\end{array}$ \\
\hline
\end{tabular}

\begin{tabular}{|c|c|c|}
\hline Das et $a l^{20}$ & $\begin{array}{l}\text { Statistics } \\
\text { calculated with } \\
\text { web-based } \\
\text { readability } \\
\text { calculator }\end{array}$ & $\begin{array}{l}\text { Privacy policy } \\
\text { readability: } \\
\text { average reading } \\
\text { grade level (12.8) } \\
\text { higher than } \\
\text { average US adult } \\
\text { level (8.0) }\end{array}$ \\
\hline
\end{tabular}

\section{Comparison Potential for Examination of Potential for} of app library social medial privacy grade as permission package names sharing: $20 \%$ listed in online requests: $82 \%$ with libraries of apps crowdsourced of apps use few relevant to social dataset permissions networks for unusual

purposes;

$10 \%$ may use

permissions in this way

\begin{tabular}{|c|c|c|c|c|}
\hline Meyer et $\left.a\right|^{23}$ & $\begin{array}{l}\text { Evaluated app } \\
\text { store page and/ } \\
\text { or downloaded } \\
\text { app manually }\end{array}$ & $\begin{array}{l}\text { Social media } \\
\text { links: } 14 \% \text { of } \\
\text { apps }\end{array}$ & $\begin{array}{l}\text { Evaluated app } \\
\text { store page and/or } \\
\text { downloaded app } \\
\text { manually }\end{array}$ & $\begin{array}{l}\text { Permission } \\
\text { requests: } \\
100 \% \text { of apps } \\
\text { Requests for } \\
\text { notifications } \\
(100 \%) \text {, } \\
\text { files/photo } \\
\text { storage }(53 \%), \\
\text { phone }(13 \%), \\
\text { microphone } \\
(8 \%) \text {, camera } \\
(7 \%) \text {; and } \\
\text { location }(4 \%) \text {. }\end{array}$ \\
\hline
\end{tabular}

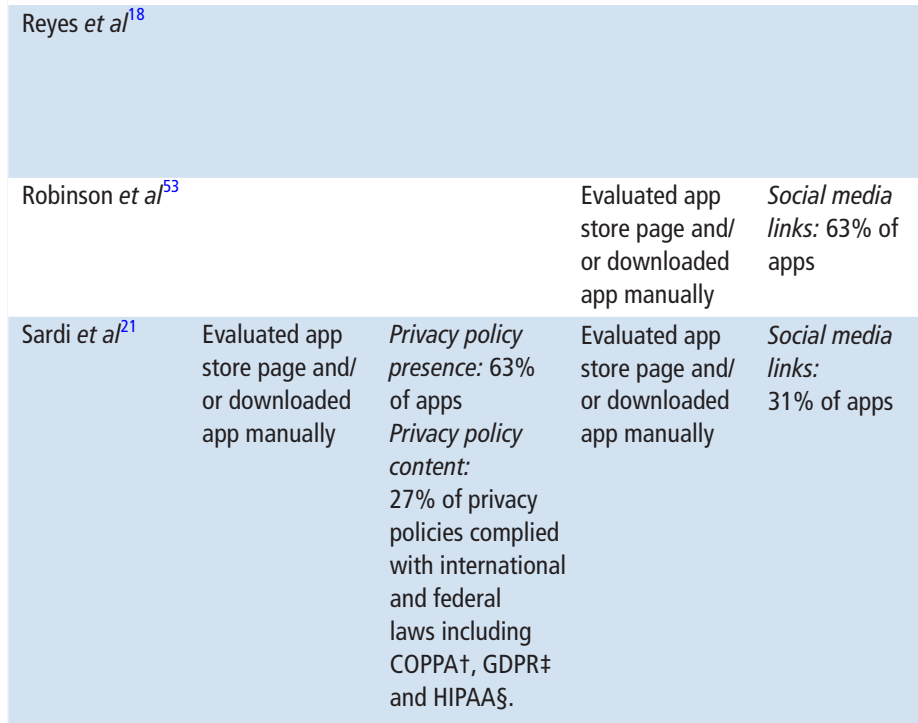

Evaluated app Login and/or password store page and/or presence: $90 \%$ of apps downloaded app required logins; $70 \%$ manually required passwords

Automated Data encryption: $40 \%$ of analysis of apps do not use TLS*

whether data

transmissions are protected

Evaluated app Login and/or password store page and/or presence: $0 \%$ of apps downloaded app manually

Evaluated app Login and/or password store page and/or presence: $29 \%$ of apps downloaded app Cloud storage backup manually option: $8 \%$ of apps 
Table 2 Continued

\begin{tabular}{|c|c|c|c|c|c|c|c|c|}
\hline & \multicolumn{2}{|l|}{ Privacy policy } & \multicolumn{2}{|l|}{ Social media } & \multicolumn{2}{|c|}{ Permissions requested } & \multicolumn{2}{|l|}{ Data security } \\
\hline & Methods & Results & Methods & Results & Methods & Results & Methods & Results \\
\hline Schoeppe et $a P^{54}$ & & & $\begin{array}{l}\text { Evaluated app } \\
\text { store page and/ } \\
\text { or downloaded } \\
\text { app manually }\end{array}$ & $\begin{array}{l}\text { Social media } \\
\text { links: } \\
60 \% \text { of apps }\end{array}$ & & & $\begin{array}{l}\text { Evaluated app } \\
\text { store page and/or } \\
\text { downloaded app } \\
\text { manually }\end{array}$ & $\begin{array}{l}\text { Login and/or password } \\
\text { presence: } 20 \% \text { of apps }\end{array}$ \\
\hline $\begin{array}{l}\text { Schoffman et } \\
a P^{55}\end{array}$ & & & $\begin{array}{l}\text { Evaluated app } \\
\text { store page and/ } \\
\text { or downloaded } \\
\text { app manually }\end{array}$ & $\begin{array}{l}\text { Social media } \\
\text { links: } \\
16 \% \text { of apps }\end{array}$ & & & & \\
\hline Virani et $a I^{58}$ & $\begin{array}{l}\text { Evaluated app } \\
\text { store page and/ } \\
\text { or downloaded } \\
\text { app manually }\end{array}$ & $\begin{array}{l}\text { Privacy policy } \\
\text { presence: } 100 \% \\
\text { of apps }\end{array}$ & & & & & $\begin{array}{l}\text { Evaluated app } \\
\text { store page and/or } \\
\text { downloaded app } \\
\text { manually }\end{array}$ & $\begin{array}{l}\text { Login and/or password } \\
\text { presence: } 33 \%-100 \% \text { of } \\
\text { apps }\end{array}$ \\
\hline Weber et $a l^{59}$ & & & $\begin{array}{l}\text { Evaluated app } \\
\text { store page and/ } \\
\text { or downloaded } \\
\text { app manually }\end{array}$ & $\begin{array}{l}\text { Social media } \\
\text { links: } \\
\text { Less than or } \\
\text { equal to } 35 \% \\
\text { of apps }\end{array}$ & & & $\begin{array}{l}\text { Evaluated app } \\
\text { store page and/or } \\
\text { downloaded app } \\
\text { manually }\end{array}$ & $\begin{array}{l}\text { Login and/or password } \\
\text { presence: } 70 \% \text { of apps }\end{array}$ \\
\hline $\begin{array}{l}\text { Zarnowiecki } \\
\text { et } a l^{63}\end{array}$ & & & $\begin{array}{l}\text { Evaluated app } \\
\text { store page and/ } \\
\text { or downloaded } \\
\text { app manually }\end{array}$ & $\begin{array}{l}\text { Social media } \\
\text { links: } \\
25 \% \text { of apps }\end{array}$ & & & $\begin{array}{l}\text { Evaluated app } \\
\text { store page and/or } \\
\text { downloaded app } \\
\text { manually }\end{array}$ & $\begin{array}{l}\text { Login and/or password } \\
\text { presence: } 0 \% \text { of apps }\end{array}$ \\
\hline
\end{tabular}

*Transport Layer Security.

†Children's Online Privacy Protection Act.

$\ddagger$ General Data Protection Regulation.

§Health Insurance Portability and Accountability Act.

\section{In-app purchasing and advertisements}

Half of our included studies evaluated apps' commercial features with results showing several areas of potential concern. In-app purchase options and advertisements are common, manipulative methods are used to deliver advertisements, and advertising information is potentially harmful to health. ${ }^{26} 34$ These issues pose a problem as research shows both parents and children may not always be able to distinguish app content from advertising. ${ }^{235}$ The content of advertisements within children's apps is also often not age-appropriate with advertisement content

Table 3 App commercial feature evaluation results

\begin{tabular}{|c|c|c|c|c|}
\hline \multirow[t]{2}{*}{ Study } & \multirow[b]{2}{*}{$\begin{array}{l}\text { Total number of } \\
\text { apps sampled }\end{array}$} & \multicolumn{3}{|c|}{ Results of commercial feature assessment } \\
\hline & & $\begin{array}{l}\% \text { of sampled apps with } \\
\text { in-app purchases }\end{array}$ & $\begin{array}{l}\% \text { of sample apps with } \\
\text { advertisements }\end{array}$ & Advertisement-related analyses \\
\hline Biviji et a/40 & 29 & $18 \%$ & $51 \%$ & \\
\hline Brown et $a l^{42}$ & 51 & $43 \%$ & & \\
\hline Chen et $a l^{44}$ & 22 & $0 \%$ & $9 \%$ & \\
\hline Cheng et $a l^{24}$ & 47 & $26 \%$ & & \\
\hline Davis et a/45 & 46 & & $13 \%$ & \\
\hline Furlong et $a l^{46}$ & 132 & $33 \%$ & & \\
\hline Liu et $a l^{22}$ & 67778 & $22 \%$ & Potential for advertisements in $53 \%$ & \\
\hline Meyer et $a l^{23}$ & 135 & $46 \%$ & $95 \%$ & $\begin{array}{l}\text { Apps included commercial characters ( } 42 \%) \text {, full-app teasers } \\
(46 \%) \text {, advertisements that interrupted gameplay }(35 \%) \text {, } \\
\text { distracting banners (17\%) or camouflaged advertisements } \\
(7 \%) \text {. Advertisements more prevalent in free apps. }\end{array}$ \\
\hline Richardson et $a^{52}$ & 18 & $6 \%$ & $17 \%$ & \\
\hline Sardi et $a l^{21}$ & 48 & $32 \%$ & & \\
\hline Schoeppe et $\left.a\right|^{54}$ & 25 & $24 \%$ & & \\
\hline Virani et $a l^{58}$ & 16 & $19 \%$ & $50 \%$ & \\
\hline Wisniewski et a/ ${ }^{61}$ & 75 & $24 \%$ & & \\
\hline Womack et a/ ${ }^{62}$ & 48 & & $63 \%$ & \\
\hline Zarnowiecki et a ${ }^{63}$ & 4 & $50 \%$ & $25 \%$ & \\
\hline Zhao et $a l^{25}$ & 26 & $46 \%$ & $85 \%$ & Most apps (77\%) promoted infant formula \\
\hline Zhao et a ${ }^{26}$ & 451 & $95 \%$ & & $\begin{array}{l}\text { Advertisements coded as being related to formula for } \\
\text { premature infants, term infants, toddlers and older children } \\
\text { including in circumstances where potentially harmful or } \\
\text { unnecessary to health }\end{array}$ \\
\hline
\end{tabular}


often exceeding developer-stated app maturity levels. ${ }^{36}$ Finally, furthering digital disparities, free apps-which parents and children of lower socioeconomic status may more frequently engage with-more frequently contain these in-app purchase options and advertisements. ${ }^{23}$

\section{Implications}

Our results have important implications for regulatory bodies, app developers and parents. Although regulations such as the GDPR and COPPA have been enacted to protect children's online privacy, our results point to the limits of these efforts. For instance, COPPA is reported as underenforced in the USA ${ }^{11}$ and, as such, non-compliance with the regulation appears widespread. ${ }^{18} 19$ These privacy regulations also rely on the idea that an informed consumer can select apps with adequate privacy protections in place. ${ }^{37}$ However, we show that privacy policies are not always present in children's apps and, when present, vary greatly in terms of readability. As such, the onus of responsibility for personal data protection is placed on those who may not be adequately equipped for privacy decision making by default (ie, the child or parent). Combined with more stringent regulatory enforcement-app developers, who may not be consistently aware of the destinations of data transmitted from their apps ${ }^{18}$ can reduce personal identifier collection in the spirit of data minimisation ${ }^{19}$ and systematically evaluate app privacy behaviours before release. ${ }^{18}$ Ahead of these needed regulatory and industry shifts, parents and older children may install apps from trusted developers, ${ }^{19}$ disable advertisement identifiers, adjust app permissions and use advertisement blockers to reduce the likelihood of privacy breaches. ${ }^{38}$

\section{Limitations}

First, although sensitive, the nature of our research question resulted in a search strategy that was imprecise and identified many irrelevant studies. We used duplicate screening and team discussions to resolve discrepancies and systematically exclude such studies. Second, even though we developed a broad search strategy, the cross-disciplinary nature of our research question may mean that we may not have located all studies accessible in disparate, discipline-focused databases. Third, although not the goal of a scoping review, we did not conduct a methodological quality assessment and instead included all identified studies.

\section{CONCLUSION}

Research related to the data handling behaviours and commercial aspects of apps that may transmit children's data is emerging but has not kept pace with the rapid expansion and evolution of the mobile ecosystem. The lack of evaluations may be related to the technical difficulty in doing so-an issue that may be solved by collaborative research efforts spanning the disciples of computer science, child health and commercial regulatory policy. These collaborations may be fruitful in rooting out and acting on risks to children's privacy and well-being within mobile ecosystems. ${ }^{19}$ Studies are needed to understand the intersection between transmitted data and advertisements within apps and how this commercial exposure effects children's health and wellbeing. Ultimately, enforced and stricter regulation may be key to protecting children's online privacy and dampening any impacts of data sharing.

\section{Twitter Lindsay Jibb @lindsayjibb}

Acknowledgements We acknowledge the support of the Government of Canada's New Frontiers in Research Fund (NFRF) (NFRFE-2019-00806)
Contributors QG conceptualised and designed the study, designed the data collection instruments, and reviewed and revised the manuscript. $L J$ designed the study, designed the data collection instruments, collected and synthesised the data, drafted the initial manuscript, and revised the manuscript. LR designed the search strategy, conducted the search, and reviewed and revised the manuscript. EA and $\mathrm{MH}$ designed the data collection instruments and collected and synthesised the data and reviewed and revised the manuscript. All authors approved the final manuscript as submitted and agree to be accountable for all aspects of the work. LJ acts as guarantor and accepts full responsibility for the finished work and the conduct of the study, had access to the data, and controlled the decision to publish.

Funding This study was funded by the Natural Sciences and Engineering Research Council of Canada, New Frontiers in Research Fund (NREF-2019-00806), Canadian Institutes of Health Research and Social Sciences and Humanities Research Council of Canada.

Disclaimer The Government of Canada had no role in the design or conduct of this study or decision to publish.

Competing interests None declared.

Patient consent for publication Not applicable.

Ethics approval Not applicable.

Provenance and peer review Not commissioned; externally peer reviewed.

Supplemental material This content has been supplied by the author(s). It has not been vetted by BMJ Publishing Group Limited (BMJ) and may not have been peer-reviewed. Any opinions or recommendations discussed are solely those of the author(s) and are not endorsed by BMJ. BMJ disclaims all liability and responsibility arising from any reliance placed on the content. Where the content includes any translated material, BMJ does not warrant the accuracy and reliability of the translations (including but not limited to local regulations, clinical guidelines, terminology, drug names and drug dosages), and is not responsible for any error and/or omissions arising from translation and adaptation or otherwise.

Open access This is an open access article distributed in accordance with the Creative Commons Attribution Non Commercial (CC BY-NC 4.0) license, which permits others to distribute, remix, adapt, build upon this work non-commercially, and license their derivative works on different terms, provided the original work is properly cited, appropriate credit is given, any changes made indicated, and the use is non-commercial. See: http://creativecommons.org/licenses/by-nc/4.0/.

\section{ORCID iD}

Lindsay Jibb http://orcid.org/0000-0001-6995-2825

\section{REFERENCES}

1 Kinsner K, Parlakian R, Sanchez GR, et al. Millennial Connections: Findings from ZERO TO THREE's 2018 Parent Survey, 2018. Available: https://www.zerotothree.org/ resources/2475-millennial-connections-executive-summary\#downloads

2 Levine LE, Waite BM, Bowman LL, et al. Mobile media use by infants and toddlers. Comput Human Behav 2019;94:92-9.

3 The Guardian. Most children own mobile phone by age of seven, study finds, 2020 Available: https://www.theguardian.com/society/2020/jan/30/most-children-ownmobile-phone-by-age-of-seven-study-finds [Accessed 23 Sep 2021].

4 Pangrazio L, Selwyn N. "It's Not Like It's Life or Death or Whatever": Young People's Understandings of Social Media Data. Soc Media Soc 2018;4:2056305118787808.

5 Vallina-Rodriguez N, Sundaresan S, Razaghpanah A. Tracking the trackers: towards understanding the mobile advertising and tracking ecosystem. In: 1st data and algorithm transparency workshop, 2016: 1-6.

6 Grundy Q, Chiu K, Held F, et al. Data sharing practices of medicines related apps and the mobile ecosystem: traffic, content, and network analysis. BMJ 2019;364:1920.

7 Huckvale K, Torous J, Larsen ME. Assessment of the data sharing and privacy practices of smartphone apps for depression and smoking cessation. JAMA Netw Open 2019;2:e192542

8 Information Commissioner's Office. Children and the UK GDPR. Available: https:// ico.org.uk/for-organisations/guide-to-data-protection/guide-to-the-general-dataprotection-regulation-gdpr/children-and-the-uk-gdpr/ [Accessed 29 Jul 2021].

9 Federal Trade Commission. Children's Online Privacy Protection Rule ("COPPA"). Available: https://www.ftc.gov/enforcement/rules/rulemaking-regulatory-reformproceedings/childrens-online-privacy-protection-rule [Accessed 29 Jul 2021].

10 Binns R, Lyngs U, Kleek MV. Third party tracking in the mobile ecosystem. 10th ACM Conference, 2018:23-31.

11 Campbell AJ. Children's privacy laws must be strengthened and enforced. JAMA Pediatr 2020:174:e203393.

12 Montgomery KC, Chester J, Milosevic T. Children's privacy in the big data era: research opportunities. Pediatrics 2017:140:S117-21.

13 Levac D, Colquhoun H, O'Brien KK. Scoping studies: advancing the methodology. Implement Sci 2010;5:69.

14 Grundy QH, Wang Z, Bero LA. Challenges in assessing mobile health app quality. Am J Prev Med 2016;51:1051-9. 
15 Tricco AC, Lillie E, Zarin W, et al. PRISMA extension for scoping reviews (PRISMA-SCR): checklist and explanation. Ann Intern Med 2018;169:467-73.

16 Mobile app, 2021. Available: https://en.wikipedia.org/wiki/Mobile_app\#cite_note-19 [Accessed 2 Jan 2022].

17 Lalloo C, Jibb LA, Rivera J, et al. "There's a pain app for that": review of patienttargeted smartphone applications for pain management. 2015;31:557-63.

18 Reyes I, Wijesekera P, Reardon J, et al. "Won't Somebody Think of the Children?" Examining COPPA Compliance at Scale. Proc Priv Enhancing Technologies 2018:2018:63-83.

19 Zhao F, Egelman S, Weeks HM, et al. Data collection practices of mobile applications played by preschool-aged children. JAMA Pediatr 2020;174:e203345.

20 Das G, Cheung C, Nebeker C, et al. Privacy policies for Apps targeted toward youth: descriptive analysis of readability. JMIR Mhealth Uhealth 2018;6:e3.

21 Sardi L, Idri A, Redman LM, et al. Mobile health applications for postnatal care: review and analysis of functionalities and technical features. Comput Meth Prog Bio 2020;184:105114.

22 Liu M, Wang H, Guo Y, et al. Identifying and analyzing the privacy of Apps for kids. 2016:105-10.

23 Meyer M, Adkins V, Yuan N, et al. Advertising in Young Children's Apps. J Dev Behav Pediatrics 2019;40:32-9.

24 Cheng $\mathrm{H}$, Tutt A, Llewellyn C, et al. Content and quality of infant feeding smartphone Apps: five-year update on a systematic search and evaluation. JMIR Mhealth Uhealth 2020:8:e17300

25 Zhao J, Freeman B, Li M. How do infant feeding Apps in China measure up? A content quality assessment. JMIR Mhealth Uhealth 2017:5:e186.

26 Zhao J, Li M, Freeman B. A baby formula designed for Chinese babies: content analysis of milk formula advertisements on Chinese parenting apps. JMIR Mhealth Uhealth 2019;7:e14219-12.

27 World Health Organization. International Code of marketing of breast-milk substitutes. Available: https://www.who.int/nutrition/publications/code_english.pdf [Accessed 30 Jul 2021].

28 Pechmann C, Levine L, Loughlin S, et al. Impulsive and Self-Conscious: Adolescents' Vulnerability to Advertising and Promotion. J Public Policy Amp Mark 2005;24:202-21.

29 In:; . Zhao J, Wang G, Dally C. 'I make up a silly name': Understanding Children'sPerception of Privacy Risks Online, 2019.

30 Desimpelaere L, Hudders L, Van de Sompel D. Children's perceptions of fairness in a data disclosure context: The effect of a reward on the relationship between privacy literacy and disclosure behavior. Telemat Inform 2021;61:101602.

31 Livingstone S, Stoilova M, Nandagiri R. Children's Data and Privacy Online: Growing up in a Digitial Age. LSE Media and Communications, 2018.

32 Tangari G, Ikram M, ljaz K, et al. Mobile health and privacy: cross sectional study. BMJ 2021;373:n1248.

33 Okoyomon E, Samarin N, Wijesekera P. On the Ridiculousness of notice and consent: contradictions in app privacy policies 2019.

34 Freeman B, Kelly B, Baur L, et al. Digital junk: food and beverage marketing on Facebook. Am J Public Health 2014;104:e56-64.

35 Wojdynski BW. The Deceptiveness of sponsored news articles. Am Behav Sci 2016:60:1475-91.

36 Chen Y, Zhu S, Xu H. Children's Exposure to Mobile In-App Advertising: An Analysis of Content Appropriateness. Int Conf Soc Comput 2013:196-203.

37 Marelli L, Lievevrouw E, Van Hoyweghen I. Fit for purpose? The GDPR and the governance of European digital health. Policy Stud 2020;41:447-67.

38 Thompson S, Warzel C. The privacy project: twelve million phones, one dataset, zero privacy. The New York Times, 2019.

39 Biviji R, Vest JR, Dixon BE. Content analysis of behavior change techniques in maternal and infant health apps. Trans/ Behav Med 2020.

40 Biviji R, Vest JR, Dixon BE, et al. Factors related to user ratings and user Downloads of mobile Apps for maternal and infant health: cross-sectional study. JMIR Mhealth Uhealth 2020;8:e15663.
41 Bland C, Dalrymple KV, White SL, et al. Smartphone applications available to pregnant women in the United Kingdom: an assessment of nutritional information. Matern Child Nutr 2020;16:e12918.

42 Brown HM, Bucher T, Collins CE, et al. A review of pregnancy iPhone apps assessing their quality, inclusion of behaviour change techniques, and nutrition information. Matern Child Nutr 2019;15:e12768.

43 Bry LJ, Chou T, Miguel E, et al. Consumer smartphone Apps marketed for child and adolescent anxiety: a systematic review and content analysis. Behav Ther 2018;49:249-61.

44 Chen E, Mangone ER. A systematic review of Apps using mobile criteria for adolescent pregnancy prevention (mCAPP). JMIR Mhealth Uhealth 2016;4:e122.

45 Davis DW, Logsdon MC, Vogt K. Parent education is changing: a review of smartphone Apps. Mcn Am J Maternal Sol Child Nurs 2017;42:248-56.

46 Furlong L, Morris M, Serry T, et al. Mobile apps for treatment of speech disorders in children: an evidence-based analysis of quality and efficacy. PLoS One 2018;13:e0201513.

47 Hotwani K, Sharma K, Nagpal D, et al. Smartphones and tooth brushing: content analysis of the current available mobile health apps for motivation and training. Eur Arch Paediatr Dent 2020;21:103-8.

48 Hswen Y, Murti V, Vormawor AA, et al. Virtual avatars, gaming, and social media: designing a mobile health app to help children choose healthier food options. J Mob Technol Med 2013;2:8-14.

49 Mousavi Jazayeri SM, Jamshidnezhad A. Top Mobile Applications in Pediatrics and Children's Health: Assessment and Intelligent Analysis Tools for a Systematic Investigation. Malays J Med Sci 2019;26:5-14.

50 Musgrave LM, Kizirian NV, Homer CSE, et al. Mobile phone Apps in Australia for improving pregnancy outcomes: systematic search on app stores. JMIR Mhealth Uhealth 2020;8:e22340.

51 Quinn M, Bliss M. Moving beyond tracing: The nature, availability and quality of digital apps to support children's writing. J Early Child Lit 2021;21:230-58.

52 Richardson B, Dol J, Rutledge K, et al. Evaluation of mobile Apps targeted to parents of infants in the neonatal intensive care unit: systematic APP review. JMIR Mhealth Uhealth 2019;7:e11620.

53 Robinson CD, Seaman EL, Grenen E, et al. A content analysis of smartphone apps for adolescent smoking cessation. Trans/ Behav Med 2020;10:302-9.

54 Schoeppe S, Alley S, Rebar AL, et al. Apps to improve diet, physical activity and sedentary behaviour in children and adolescents: a review of quality, features and behaviour change techniques. Int J Behav Nutr Phys Act 2017;14:83.

55 Schoffman DE, Turner-McGrievy G, Jones SJ, et al. Mobile apps for pediatric obesity prevention and treatment, healthy eating, and physical activity promotion: just fun and games? Trans/ Behav Med 2013;3:320-5.

56 Sidhu S, Ma K, Sadovnikova A. Features and educational content related to milk production in breastfeeding Apps: content analysis informed by social cognitive theory. JMIR Pediatr Parent 2019;2:e12364.

57 Taki S, Campbell KJ, Russell CG, et al. Infant feeding websites and Apps: a systematic assessment of quality and content. Interact J Med Res 2015;4:e18.

58 Virani A, Duffett-Leger L, Letourneau N. Parenting apps review: in search of good quality apps. Mhealth 2019;5:44

59 Weber SJ, Dawson D, Greene H, et al. Mobile phone Apps for low-income participants in a public health nutrition program for women, infants, and children (WIC): review and analysis of features. JMIR Mhealth Uhealth 2018;6:e12261.

60 Weekly T, Walker N, Beck J, et al. A review of Apps for Calming, relaxation, and mindfulness interventions for pediatric palliative care patients. Children 2018;5:16.

61 Wisniewski P, Ghosh AK, Xu H. Parental control vs. teen self-regulation: is there a middle ground for mobile online safety? Proc $2017 \mathrm{Acm}$ Conf Comput Supported Cooperative Work Soc Comput, 2017:51-69.

62 Womack JJ, Anderson LN, Ledford CJW. Presence of complex and potentially conflicting information in prenatal mobile Apps. Health Promot Pract 2020;21:238-45

63 Zarnowiecki D, Mauch CE, Middleton G, et al. A systematic evaluation of digital nutrition promotion websites and apps for supporting parents to influence children's nutrition. Int J Behav Nutr Phys Act 2020;17:17. 